\title{
37 Data-based assessment of psychological wellbeing in whole school environments
}

\author{
Beth Doll
}

\section{How to use this policy}

The social and academic success of students is stronger when they learn in schools with learning environments that support the psychological wellbeing and resilience of students. However, even as schools work to strengthen their social and psychological climate, they typically evaluate their effectiveness by examining data describing behaviour problems. In contrast, this policy describes optimal practices for assessing positive psychological wellbeing in whole school environments, yielding useful data for making decisions about school improvement practices and monitoring the impact of these efforts over time. This allows schools to prioritize the aspects of their learning environments that are most in need of improvement and to efficiently focus on improvement strategies that are working. This policy example is intentionally broad, and school policy creators are encouraged to delete and build upon suggestions below to create a policy that best represents their school.

[To adapt and use this policy, delete or modify the text as indicated]

\section{[INSERT name of school] Data-based assessment of psychological wellbeing in whole school environments}

\section{Rationale}

This policy addresses the use of school-wide assessment to facilitate and maintain school environments that foster students' psychological wellbeing and resilience. The importance of schools' social and psychological environments was demonstrated as early as the 1960s, with evidence linking positive school or classroom climates to higher achievement, better attendance, fewer behaviour problems, and stronger mental health (Fraser, 1998; Thapa et al., 2013; Zullig et al., 2010). A recurring and related finding of developmental risk and resilience research is that wellbeing can be prompted, even in the face of exceptional risk, when children develop in settings with strong and caring 
relationships, support for their developing autonomy and self-regulation, and support for their emotional regulation and joy (Masten, 2014; Theron, 2016). Educational and psychological scholars have emphasized the responsibility that schools hold for integrating these social and psychological supports into the infrastructure of schools, where children will spend 15,000 hours over the course of their lifetime (Cohen et al., 2015; Masten, 2014; Rutter, 2002; Werner, 2013).

Implementing social and psychological supports into school environments requires that schools recognize the social and psychological supports that are important to student success and, (1) determine the degree to which these supports are or are not already present in the school, and (2) monitor the impact of school improvement efforts on students' experience of the school climate. This policy focuses on these tasks by detailing the assessment practices required for a defensible, data-based examination of the school's social and psychological environment. Options for data-based assessments of school environments are numerous, but only a very few have evidence attached to them (Cohen et al., 2009; Fraser, 1998; Zullig et al., 2010). Optional assessments of school learning environments that are both technically sound and pragmatically feasible can be found in the National Center for Safe and Supportive Learning Environments (https://safesupportivelearning.ed.gov); the Collaborative for Academic, Social and Emotional Learning (https://measuringsel.casel.org/ assessment-guide); and Doll (in press).

\section{Purpose}

This policy details practices for accurate and useful assessment of students' psychological wellbeing in a school, so that these assessments support focused, data-based planning for school improvement efforts and enable monitoring the progress of these efforts over time.

\section{Scope}

This policy applies to school leadership, teaching staff, students, and families. [INSERT specific roles and responsibilities of individuals or teams]

\section{Policy statement}

[INSERT name of school] assesses the collective wellbeing of students by classroom, grade level, school, and district.

Long-standing evidence has demonstrated that when social and psychological environments of classrooms and schools are positive and promote wellbeing, the academic and behavioural success of students is stronger, and students' mental health is strengthened (Bear, 2011; Thapa et al., 2013; Zullig et al., 2010). 
Our school asks students to complete brief, anonymous assessments of their experience of their school learning environment. Results are used by teachers, administrators, and students to systematically promote a psychologically healthy school climate (Cohen et al., 2015; Doll et al., 2014). We will use regular assessment of the school's psychological health to focus our school improvement efforts towards the most important goals and to track the progress of our school improvement efforts over time (Doll, 2021).

Our school has selected an assessment that examines aspects of the learning environment that are most important for students' collective school success: relationships with teachers and with peers, confident expectations that they can succeed, belief in their capacity to manage their own behaviour, and commitment to the meaningfulness of schooling (Furlong et al., 2014; Masten, 2014; Thapa et al., 2013).

To minimize the resources required for assessment, our school has selected a practical assessment that is brief (requiring less than 15 minutes of student time), easy to administer, directly related to our school and classroom practices, available at low or no cost, and easily translated into results (Christ \& Nelson, 2014; Dart et al., 2019). Examples of whole school assessments that are practical, with evidence of appropriate technical soundness include: the Social and Emotional Health Survey (Furlong et al., 2014), the Delaware School Climate Survey (Bear et al., 2011), the US Department of Education School Climate Survey (National Center for Educational Statistics, 2015), and the ClassMaps Survey (Doll et al., 2014).

To ensure the accuracy and usefulness of our assessment results, we have selected an assessment that has evidence of reliability and validity that has been published in professional journals and reviewed by qualified peers (Christ \& Nelson, 2014).

Our school notifies parents each time an assessment is collected at least two weeks in advance (Eklund et al., 2021). Copies of the assessment questions are available for parents to review, and parents can ask that their student not be included in the assessment by contacting the school office at [INSERT contact information here]. Students are encouraged to participate but may elect to not participate in the assessment. Results of the assessment will be aggregated by class, grade, or school so that no single student's response can be identified.

Our school collects the assessment of students' collective wellbeing at least twice annually, and results are reported in a form that is easily understood by teachers, students, and parents (Dart et al., 2019; Doll et al., 2014). Teachers and administrators will reflect on and discuss the results and plan modifications of school and classroom practices in response to these results. Parents may review the results upon request.

Students in our school participate in reviewing and discussing results of the assessment and have the opportunity to recommend modified school practices in response to these. Including students as partners in the ongoing assessment and modification of school learning environments contributes to the impact 
of environmental interventions, builds student competence as self-directed learners, and strengthens student engagement in the assessment and intervention actions (Cohen et al., 2014; Doll, in press).

\section{Rating of evidence base}

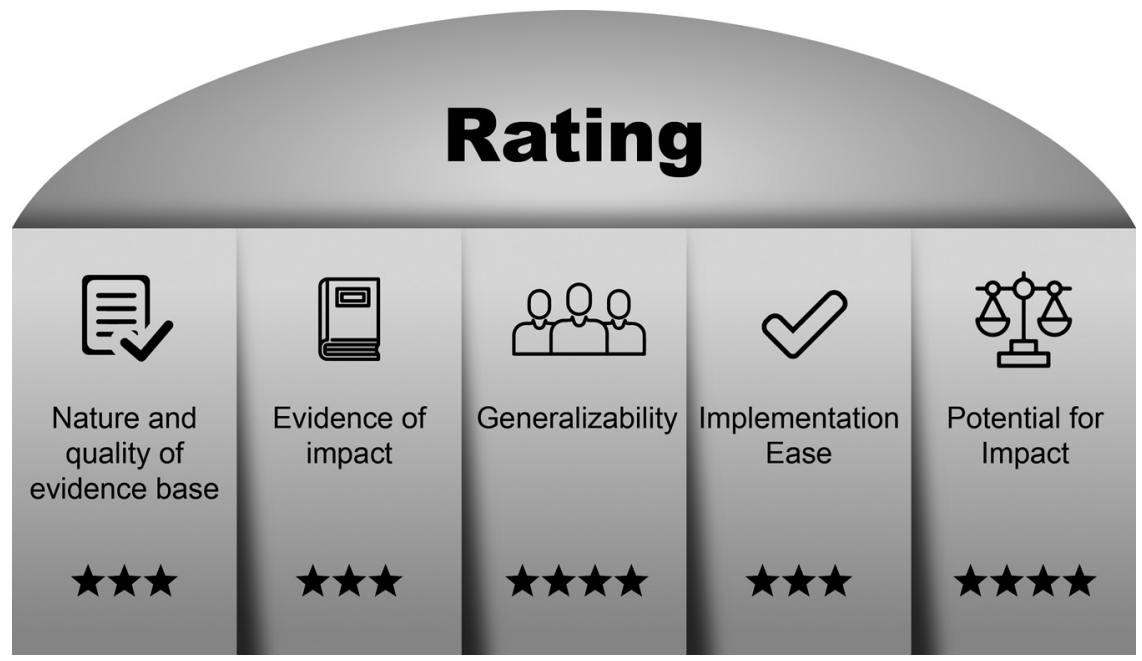

Figure 37.1. Data-based assessment of psychological well-being in whole school environments Rating of Evidence.

Author Note. Assessment of the positive psychological attributes of school environments is relatively recent, but results have consistently supported the importance of these (Bear et al., 2011; Furlong et al., 2014). School climate research since the 1960s has established repeatedly that stronger school climates result in more student success. The research that has been done on school climates and positive school learning environments has principally been in diverse schools and districts, nationally and internationally. Implementing this assessment policy is not difficult, but it is outside the range of tasks that most schools typically provide. Assessment of psychological wellbeing in school environments has the potential to re-engage students more fully in schooling by focusing on school improvement efforts and quickly identifying when efforts are working.

\section{Authorship}

Dr Beth Doll, University of Nebraska Lincoln

[INSERT RELEVANT STAFF MEMBERS]

\section{Related policy and documents}

[INSERT RELEVANT POLICY AND DOCUMENTS] 
School improvement plan

School discipline policy

Parent and family engagement policy

\section{Date of ratification}

This policy was ratified on the [INSERT DATE].

\section{Date of review}

This policy will be reviewed by [INSERT DATE].

\section{Further reading}

Cohen, J., Espelage, D. L., Twemlow, S. W., Berkowitz, M. W., \& Comer, J. P. (2015). Rethinking effective bully and violence prevention efforts: Promoting healthy school climates, positive youth development, and preventing bully-victim-bystander behavior. International Journal of Violence and Schools, 15, 2-40.

Masten, A. S. (2014). Ordinary magic: Resilience in development. New York: Guilford Press.

National Research Council and Institute of Medicine. (2004). Engaging schools: Fostering high school students' motivation to learn. Washington, DC: The National Academies Press..

Werner, E. E. (2013). What can we learn about resilience from large-scale longitudinal studies? In S. Goldstein and R. B. Brooks (Eds.), Handbook of Resilience in Children (pp. 87-102). New York: Springer.

\section{Promising options for whole school assessments}

Social and Emotional Health Survey (Furlong et al., 2014). https://www. covitalityucsb.info/sehs-measures/

Delaware School Climate Survey (Bear et al., 2011). http://wh1.oet.udel.edu/p bs/school-climate/de-school-climate-survey/

U. S. Department of Education School Climate Survey (National Center for Educational Statistics, 2015). https://safesupportivelearning.ed.gov/edscls

ClassMaps Survey (Doll et al., 2014). https://k12engagement.unl.edu/Nudata/ DB1/ClassMaps $\% 20$ Survey $\% 20$ Template.pdf

\section{References}

Bear, G. G., Gaskinsm, C., Blank, J., \& Chen, F. F. (2011). Delaware school climate survey - student: Its factor structure, concurrent validity and reliability. Journal of School Psychology, 49, 157-174. 
Christ, T. J., \& Nelson, P. M. (2014). Developing and evaluating screening systems: Practical and psychometric considerations. In R. J. Kettler, T. A. Glover, C. A. Albers, \& K. A. Feeney-Kettler (Eds.), Universal screening in educational settings: Evidence-based decision making for schools (pp. 79-110). Washington, DC: American Psychological Association.

Cohen, J., Espelage, D. L., Twemlow, S. W., Berkowitz, M. W., \& Comer, J. P. (2015). Rethinking effective bully and violence prevention efforts: Promoting healthy school climates, positive youth development, and preventing bully-victim-bystander behavior. International Journal of Violence and Schools, 15, 2-40.

Dart, E. H., Arora, P. G., Collins, T. A, \& Doll, B. (2019). Progress monitoring measures for internalizing symptoms: A systematic review of the peer-reviewed literature. School Mental Health. 11(2), 265-275.

Doll, B., Brehm, K., \& Zucker, S. (2014). Resilient classrooms: Creating healthy environments for learning (2nd ed). New York: Guilford Publications.

Doll, B. (in press). Integrating assessment into school environments to promote students' psychological well-being. In M. Furlong, K. Allen, \& D. Vella-Brodrick (Eds.), Handbook of positive psychology in schools (2nd ed.). New York: Taylor and Francis.

Eklund, K., Kilgus, S. P., Meyer, L., \& Barber, A. (2021). Universal screening to monitor students' emotional, academic and behavioral health. In P. J. Lazarus, S. Suldo, \& B. Doll (Eds.), Fostering the emotional well-being of our nation's youth: A school based approach, (pp.481-502). New York: Oxford University Press.

Fraser, B. J. (1998). Classroom environment instruments: Development, validity and applications. Learning Environments Research, 1, 7-33.

Furlong, M. J., You, J., Renshaw, T. L., Smith, D. C., \& O’Malley, M. D. (2014). Preliminary development and validation of the social and emotional health survey for secondary school students. Social Indicators Research, 117, 1011-1032.

Masten, A. S. (2014). Ordinary magic: Resilience in development. New York: Guilford Press.

National Center for Educational Statistics. (2015, August). ED school climate surveys (EDSCLS) national benchmark study 2016. National Center for Educational Statistics. https://files.eric.ed.gov/fulltext/ED577461.pdf

Rutter, M., \& Maughan, B. (2002). School effectiveness findings, 1979-2002. Journal of School Psychology, 40, 451-475.

Thapa, A., Cohen, J., Guffey, S., \& Higgins-D'Alessandro, A. (2013). A review of school climate research. Review of Educational Research, 83(3), 357-385.

Theron, L. C. (2016). The everyday ways that school ecologies facilitate resilience: Implications for school psychologists. School Psychology International, 37(2), 87-103.

Werner, E. E. (2013). What can we learn about resilience from large-scale longitudinal studies? In S. Goldstein \& R. B. Brooks (Eds.), Handbook of resilience in children (pp. 87-102). New York: Springer.

Zullig, K. J., Koopman, T. M., Patton, J. M., \& Ubbes, V. A. (2010). School climate: Historical review, instrument development, and school assessment. Journal of Psychoeducational Assessment, 28(2), 139-152. 